\title{
Mineração de Conteúdo em Mídias Sociais: análise de conteúdos publicados por usuários sobre atrativos turísticos de Curitiba-PR
}

Social Media Content Mining: a content analysis of published posts about tourist attractions in Curitiba-PR

Guilherme Mendes Thomaz (guimendesthomaz@gmail.com) Mestre, Universidade Federal do Paraná, São José do Rio Preto - SP

Alexandre Augusto Biz (bizdetur@gmail.com)

Doutor, Universidade Federal do Paraná, Florianópolis - SC

Eduardo Michelotti Bettoni (eduardo@odois.org)

Mestre, Universidade Federal do Paraná, Curitiba - PR

Luiz Mendes Filho (luiz.mendesfilho@gmail.com)

Doutor, Universidade Federal do Rio Grande do Norte, Natal - RN

\section{RESUMO}

As mídias sociais assumiram papel prioritário como fonte de informação estratégica para organizações turísticas, o que demanda o desenvolvimento de métodos, técnicas e ferramentas para se converterem em maior competitividade. Para auxiliar a gestão dos destinos turísticos por meio das mídias sociais, foi proposta nesse estudo uma metodologia de mineração de conteúdos dividida em sete fases. Para tanto, inicialmente foi realizada um levantamento dos métodos, técnicas e conceitos em mineração de conteúdo, aplicados direta ou indiretamente no Turismo. Ainda, foram investigados outros modelos similares para dar base à metodologia proposta. A validação ocorreu no período da Copa do Mundo FIFA 2014, tendo como objeto o destino Curitiba (Brasil). Foi aplicada às mensagens publicadas na mídia social Twitter, que tivessem os termos dos atrativos turísticos do município. Durante o processo foi realizada uma análise de conteúdo em uma amostra mensagens ( $n=942)$, o que permitiu identificar opiniões por meio de comentários positivos e negativos, além de características do comportamento do consumidor em turismo nas mídias sociais. O processo também se mostrou eficaz para coletar conteúdos relevantes e identificar assuntos populares, algo que pode auxiliar as Destination Management Organizations - DMO na gestão dos destinos, como auxílio suporte à tomada 
de decisões estratégicas e operacionais, além da promoção da inovação produtos, serviços e marketing. Permitiu ainda servir tanto como instrumento confirmatório, ou seja, para monitorar conteúdos a partir de uma ontologia pré-existente, quanto para identificar tendências que a extrapolem.

Palavras-chave: mídias sociais; mineração de conteúdos; atrativos turísticos; gestão de destinos turísticos; Copa do Mundo FIFA 2014.

\section{ABSTRACT}

Social media has assumed a priority role as a source of strategic information for tourism organizations which demands the development of methods, techniques and tools to become more competitive. In order to support tourism destination management through social media, a content mining method was proposed in seven phases. For this, a set of methods, techniques and concepts in content mining applied directly or indirectly in Tourism among other similar models were investigated and analyzed to provide a basis for the proposed method. The validation took place during the FIFA World Cup 2014, having the destination Curitiba (Brazil) as object. It was applied to Twitter posts (tweets) which had the terms of the city's main tourist attractions. During the process, a content analysis was carried on a sample of messages $(n=942)$ that allowed to identify opinions, positive and negative comments, and many other consumer behavior characteristics in tourism and social media. The validation took place in the period of the 2014 FIFA World Cup, with the purpose of the destination Curitiba (Brazil). It was applied to the messages published in the social media Twitter that had the terms of the tourist attractions of the municipality. During the process a content analysis was performed on a sample of messages ( $n=942)$, which allowed to identify opinions through positive and negative comments, as well as characteristics of consumer behavior in tourism in social media. The process also proved to be effective to collect relevant content and identify popular topics that can assist Destination Management Organizations - DMO in managing destinations, support strategic and operational decision-making process, innovation in product, services, marketing and tourism promotion. It has also proved to be a confirmatory instrument to monitor content from a pre-existing ontology and to identify trends that go beyond.

Keywords: social media; content mining; tourist attractions; tourism destination management; FIFA World Cup 2014.

\section{INTRODUÇÃO}

O advento da Web 2.0, principalmente no desdobramento da criação e popularização das mídias sociais, ocasionou mudanças e transformações significativas na atividade turística, sobretudo em relação à produção e 
compartilhamento de conteúdo por usuários, ganhando popularidade entre as atividades online dos viajantes (Xiang \& Gretzel, 2010).

Este conteúdo é um conjunto de informações novas e emergentes que são criadas, iniciadas, disseminadas e utilizadas por outros usuários e consumidores nas mídias sociais em forma de textos, imagens, vídeos, áudios. Envolvem conversas, análises, fatos, opiniões, avaliações, impressões, sentimentos, rumores e experiências para informar e educar outros consumidores sobre produtos, marcas, serviços, problemas e acontecimentos (Kaplan \& Haenlein, 2010; Gretzel \& Yoo, 2008).

A ampla adoção de mídias sociais por usuários e organizações gerou um aumento exponencial de dados que oferecem, não de maneira unânime, oportunidades de serem tratados e transformados em informações e conhecimentos para determinados atores sociais, como as organizações. A informação pode auxiliar no processo decisório, especialmente no planejamento e na gestão, desde que seu significado ou valor possa ser identificado em meio a vastidão de conteúdo disponível. A extensão do volume de dados é grande ao ponto que nem mesmo os sistemas corporativos convencionais (hardware e software) apresentam capacidade para trata-los, configurando-se como um desafio o desenvolvimento de técnicas e ferramentas adequadas. Ao efetivo controle e trato dessa problemática é utilizado o termo mineração de conteúdos em mídias sociais, ou Social Media Mining (SMM) (Zafarani, Abbasi \& Liu, 2014; Dey, Haque, Khurdiya \& Shroff, 2011 ; Zeng, Chen, Lusch \& Li, 2010; Sakaki, Okazaki \& Matsuo, 2010).

Por serem responsáveis pelo planejamento, gestão, promoção e desenvolvimento da atividade turística em seus respectivos destinos, é fundamental que as Destination Management Organizations (DMO) - Órgãos Oficiais de Turismo (OOT) - estejam atentas as oportunidades que as mídias sociais e seu ambiente oferecem, haja vista que o Turismo também pertence ao rol de atividades - como a maioria - que passou a ser afetada diretamente com a Web 2.0, desde a escolha de um produto (destino) até o pós-consumo. 
Sendo assim, na presente pesquisa foi abordada a importância da mineração de conteúdos em mídias sociais pelas DMO, para que essa fonte de informação possa ser investigada e posteriormente utilizada estrategicamente como instrumento de suporte à gestão, fomento, desenvolvimento e planejamento da atividade turística.

O estudo foi realizado com objetivo de propor uma metodologia de mineração de conteúdos em mídias sociais para auxiliar na gestão de destinos, resultado em uma composição de sete fases, testada no período da Copa do Mundo FIFA 2014 com uma amostra de 942 publicações do Twitter, relacionadas aos atrativos turísticos de Curitiba.

\section{GESTÃO DE DESTINOS TURÍSTICOS}

As Destination Management Organization - DMO são responsáveis por envolver a colaboração entre as várias partes e atores locais envolvidos no planejamento, gestão, promoção do destino turístico e pelas atividades de integração, cooperação e coordenação em um nível público-privado.

A abordagem holística para a gestão de destinos turísticos é aquela explorada pelas DMOs, incluindo uma vasta gama de responsabilidades como planejamento, desenvolvimento e promoção do destino turístico a nível estratégico e tático. Dentre principais funções estão: (i) coordenar estratégias de marketing, incluindo a marca turística do destino, bem como a gestão de informação e conhecimento sobre o destino; (ii) estabelecer redes e iniciativas para melhorar a oferta turística do destino; e (iii) coordenar o planejamento e desenvolvimento do turismo (Ritchie \& Crouch, 2003).

Dwyer et al. (2009, p. 66) destacam que a inovação tecnológica é identificada como um dos principais pilares da vantagem competitiva para destinos turísticos ao afirmarem que "[...] os gestores de turismo de sucesso deve ser capaz de imaginar, perceber e avaliar os efeitos da ciência e da tecnologia que se aproxima sobre demanda, oferta e distribuição". A 
expansão das tecnologias de informação e comunicação (TICs) resultou no aumento da adoção de mídias sociais por organizações turísticas e resultou em uma demanda crescente por conectividade e integração impulsionada por consumidores cujos negócios têm se tornado cada vez mais baseada na colaboração e interação.

As organizações turísticas devem estar presentes e conectar-se com usuários e consumidores em diversas mídias sociais regularmente. Considerando o leque de oportunidades, o impacto significativo e potencial de alcance das mídias sociais, cabe a elas incentivar o compartilhamento de conteúdo e a inserção de avaliações e recomendações por meio das mídias sociais, complementando os canais tradicionais. Com isso, os consumidores engajados podem aproveitar a oportunidade para compartilhar sua experiência com os outros, bem como expressar o sentimento de orgulho da marca, produto, serviço ou destino turístico (So, King, Sparks \& Wang, 2014).

\section{MÍDIAS SOCIAIS E SUA APLICAÇÃO EM DMOS}

Os conteúdos gerados por usuários acabam despertando desejos, expectativas e percepções nos demais, provocando influência no processo de tomada de decisão de compra de produto, serviço ou destino turístico. Os consumidores em potencial acessam o conhecimento desejado de diferentes fontes, bem como aproveitam as experiências de outros, para a partir disso, obter informações e vantagens para a sua própria experiência (Gretzel \& Yoo, 2008; Roque, Fernandes \& Raposo, 2012)

Além disso, a adoção de mídias sociais por viajantes para publicar avaliações (reviews) e conteúdos relacionados às suas viagens, bem o comportamento de busca por comentários/opiniões publicadas online para planejamento da própria viagem, são aspectos reconhecidos em diversos estudos (Gretzel \& Yoo, 2008; Carson, 2008; Xiang \& Gretzel, 2010; Pulvirenti \& Jung, 2011). 
Todas estas mudanças vêm impactando na atividade turística e alterando não só modo em que as pessoas pesquisam, planejam, compram e consomem, mas também alterando os processos de organização, planejamento, gestão e promoção de organizações turísticas públicas e privadas. Os destinos turísticos e as DMO também são impactados por esse processo de mudança, pois a competitividade dos mesmos é associada à sua capacidade de satisfazer as necessidades de informação dos turistas, seja em portais web, mídias sociais ou qualquer outro formato / canal.

Perante esta realidade, Roque, Fernandes e Raposo (2012) afirmam que é fundamental que as organizações responsáveis pela gestão e promoção de destinos turísticos (as DMOs) compreendam a necessidade de utilizar TICs para impulsionar o desenvolvimento, competitividade e sustentabilidade do destino. As mídias sociais estão inseridas nesse meio, uma vez que oferecem ferramentas que facilitam a comunicação entre organização e consumidor, contexto que já chega a ser explorado por algumas DMOs. Esta e outras abordagens sobre a importância e vantagens da utilização das mídias sociais são discutidas no tópico seguinte.

As mídias sociais oferecem oportunidades às DMO para reformular o seu modelo de negócios, atividades, tarefas, processos e operações (reengenharia), também para o desenvolvimento de novos produtos e serviços, marketing, redes e gestão do conhecimento. Além disso, as mídias sociais tem provado ser uma excelente estratégia para promoção de produtos, serviços e destinos turísticos (Zeng \& Gerritsen, 2014).

A ampla adoção das mídias sociais por pessoas e organizações ocasionou uma rica quantidade de dados e informações que ao serem tratados e analisados oferecem oportunidades para serem transformados em conhecimento para as organizações. Isso resultou na necessidade das organizações em monitorar o conteúdo, bem como o desempenho e resultados das estratégias adotadas nas mídias sociais (Uden et al., 2013; He, Zha \& Li, 2013). 
Além de elaborar estratégias de marketing e promoção inovadoras, as DMO podem adotar o monitoramento do destino na Internet e nas mídias sociais com o objetivo de identificar o que está sendo falado (positiva e negativamente); quem são os consumidores, onde estão, o que procuram, quais foram as experiências, opiniões, preferências, comentários e comportamento dos consumidores e usuários online, entre outros.

\section{MONITORAMENTO EM MÍDIAS SOCIAIS E O TURISMO}

O monitoramento em mídias sociais é uma estratégia emergente que tem como objetivo extrair informações relevantes de conteúdos não estruturados, exigindo acompanhamento e refinamento de informações contínuo para alcançar bons resultados (Zeng, Li \& Duan, 2012). Em outras palavras, o objetivo do monitoramento é saber "quem" está falando sobre o que, quando e em qual sentido (Hu \& Liv, 2004).

Os conteúdos publicados nas mídias sociais são uma importante fonte de informação e de grande relevância para pessoas, governos, empresas e organizações. À medida que as organizações estabelecem presença nas mídias sociais, não somente monitoram sua própria presença online (coletando e analisando os dados), como também precisam fazê-lo em relação aos concorrentes. Assim, avaliam o seu desempenho e podem aumentar a sua vantagem competitiva com base nessa avaliação (Paine, 2001; He, Zha \& Li, 2013).

Para sintetizar os diversos benefícios e oportunidades que as mídias sociais podem oferecer às organizações, com base na literatura de referências, foi construída a Tabela 1.

Tabela 1. Oportunidades e benefícios do monitoramento em mídias sociais

\begin{tabular}{|l|lr|}
\hline \multicolumn{1}{|c|}{ Oportunidades e Benefícios } & \multicolumn{2}{|c|}{ Autores } \\
\hline Relacionamento: relacionar-se com os usuários e consumidores; & Hea, Zha \& Li (2013); \\
solucionar queixas e preocupações dos clientes em tempo & Munar (2012); Paine \\
hábil para encurtar a duração de uma crise e evitar má & $(2011)$ \\
reputação. O monitoramento em mídias sociais é econômico & \\
comparado ao custo de reconstruir relacionamentos ou & \\
reputação. & \\
\hline
\end{tabular}




\begin{tabular}{|c|c|}
\hline $\begin{array}{l}\text { Análise competitiva: entender e identificar o que e como os } \\
\text { concorrentes estão fazendo; melhor compreender os produtos } \\
\text { e serviços dos concorrentes; identificar vantagens, fraquezas, e } \\
\text { oportunidades; aumentar o conhecimento sobre a indústria ou } \\
\text { área de atuação; alavancar efetividade e adquirir vantagem } \\
\text { competitiva. }\end{array}$ & $\begin{array}{l}\text { He, Zha \& Li (2013); Dey, } \\
\text { Haque, Khurdiya \& Shroff } \\
\text { (2011); Governatori \& } \\
\text { lannella (2011) }\end{array}$ \\
\hline $\begin{array}{l}\text { Análise de sentimento/opinião: analisar as avaliações, opiniões } \\
\text { e sentimentos dos usuários sobre organizações, produtos e } \\
\text { serviços para prever tendências, melhorar o trabalho, auxiliar no } \\
\text { processo de tomada de decisão, gestão, inteligência de } \\
\text { marketing e benchmarking do produto ou serviço. }\end{array}$ & $\begin{array}{l}\text { Pol, Patil, Patankar \& Das } \\
\text { (2008); Han, Pei \& Kamber } \\
\text { (2011); Munar (2012) }\end{array}$ \\
\hline $\begin{array}{l}\text { Descoberta de conhecimento: Detectar e descobrir novos } \\
\text { conhecimentos, padrões, características; identificar assuntos e } \\
\text { temas populares; encontrar novas oportunidades, entre outros. }\end{array}$ & $\begin{array}{l}\text { He, Zha e Li (2013); Dey, } \\
\text { Haque, Khurdiya \& Shroff } \\
\text { (2011); Governatori \& } \\
\text { lannella (2011) }\end{array}$ \\
\hline $\begin{array}{l}\text { Conhecimento do consumidor (Costumer Knowledge } \\
\text { Management - CKM): obter conhecimento sobre os } \\
\text { consumidores para melhor compreender seus } \\
\text { comportamentos, características, opiniões e preferências; } \\
\text { como reagem a mudanças; identificar sugestões e } \\
\text { necessidades para melhorar, criar e inovar produtos e serviços; } \\
\text { melhorar a satisfação e fidelização. }\end{array}$ & $\begin{array}{l}\text { He, Zha e Li (2013); } \\
\text { Chua (2011); Chua \& } \\
\text { Bannerjeer (2013); } \\
\text { Magnier-Watanabe, } \\
\text { Yoshida \& Watanabe } \\
\text { (2010) }\end{array}$ \\
\hline $\begin{array}{l}\text { Criação e inovação em produtos e serviços: identificar como } \\
\text { produtos e serviços são recebidos pelos consumidores para } \\
\text { auxiliar no desenvolvimento, criação e inovação de novos } \\
\text { produtos e serviços. }\end{array}$ & $\begin{array}{l}\text { Chua (2011); Chua e } \\
\text { Bannerjee (2013); } \\
\text { Coutinho, Lang \& } \\
\text { Mitschang (2013) }\end{array}$ \\
\hline $\begin{array}{l}\text { Previsão de cenários, tendências e eventos: realizar análises } \\
\text { qualitativas e quantitativas para identificar mudanças, cenários } \\
\text { e até mesmo prever eventos futuros. }\end{array}$ & $\begin{array}{l}\text { Yu e Kak (2012); He, Zha e } \\
\text { Li (2013); }\end{array}$ \\
\hline $\begin{array}{l}\text { Tomada de decisão/gestão: utilizar as informações adquiridas } \\
\text { nas mídias sociais para auxiliar no processo de tomada de } \\
\text { decisões operacionais e estratégicas; planejamento, } \\
\text { implementação de ações e direcionamento de investimentos } \\
\text { futuros. }\end{array}$ & $\begin{array}{l}\text { Lau (2005); Han, Pei \& } \\
\text { Kamber (2011); }\end{array}$ \\
\hline $\begin{array}{l}\text { Estratégia: mensurar e monitorar as ações implementadas para } \\
\text { alcançar os objetivos; gerenciar e mapear o sucesso e falhas } \\
\text { das estratégias; procurar referências e resultados das ações e } \\
\text { estratégias elaboradas; ajustar as estratégias em mídias sociais; } \\
\text { elaborar novas estratégias de marketing, promoção, entre } \\
\text { outras. }\end{array}$ & $\begin{array}{l}\text { Torres (2009); Munar } \\
\text { (2012); Hea, Zha \& Li } \\
\text { (2013) }\end{array}$ \\
\hline
\end{tabular}

Fonte: Elaborado pelos autores (2016)

A ausência de entendimento e atenção desse cenário com as mídias sociais no Turismo é um fator muito limitante na inteligência competitiva das organizações. As mídias sociais podem ser uma ferramenta de marketing extremamente eficaz para monitorar o feedback dos visitantes sobre as suas férias, compreender e conhecer as opiniões dos consumidores sobre os destinos, identificar forças e fraquezas do plano de marketing e das estratégias 
de promoção turística, bem como identificar e conhecer a imagem criada e percebida do destino na mente dos consumidores (Carson, 2008; Xiang \& Gretzel, 2010).

Os gestores podem monitorar tendências e as percepções de turistas sobre determinado destino turístico, identificar o aumento ou diminuição do interesse dos mesmos em relação a atrações turísticas ou tipos de turismo específicos, identificar relatos e histórias positivas publicadas pelos usuários sobre o destino para utilizá-las em campanhas publicitárias e estratégias de marketing e até mesmo identificar e examinar conteúdos negativos para gestão da qualidade do destino (Munar, 2012).

Além disso, a identificação de opiniões negativas e positivas nas mídias sociais podem auxiliar as organizações em suas diretrizes de mudança e criação de estratégias, usuários e clientes a decidir sobre a compra de um produto, serviço ou local de destino para suas férias e organizações governamentais a melhorar os serviços, campanhas de lançamento, entre outros (Ku \& Chen, 2007). Sendo assim, a compreensão antecipada e oportuna dos conteúdos gerados pelos usuários nas mídias sociais tornou-se prioridade para as organizações e resultou no aparecimento de aplicações e ferramentas de monitoramento e análise de mídias sociais (Coutinho, Lang \& Mitschang, 2013).

Através da utilização de técnicas de computação automatizadas para exploração de dados, foi possível desenvolver aplicações para coletar e extrair informações úteis e conhecimentos a partir de um grande número de documentos textuais - como nas mídias sociais - com o objetivo de subsidiar o processo decisório de uma organização (He, Zha \& Li, 2013).

Portanto, o monitoramento em mídias sociais oferece oportunidades para identificar a opinião e sentimento dos turistas sobre destinos, produtos, serviços turísticos; monitorar eventos e situações cotidianas para identificar pontos fracos, fortes, oportunidades e situações críticas. Essas informações dão suporte a gestão do destino turístico na definição de prioridades, 
direcionamento de investimentos, criação de políticas públicas e cursos de capacitação; redefinição de estratégias de marketing e promoção turística, posicionamento, entre outros.

Entre as técnicas que têm sido investigadas para extrair informações e conhecimentos nas mídias sociais, há destaque para mineração de dados e análise de conteúdo por fornecerem recursos para o trato de grandes conjuntos de dados textuais complexos e dinâmicos, característicos de mídias sociais (Santos, 2009; He, Zha \& Li, 2013).

\section{MINERAÇÃO DE CONTEÚDO EM MÍDIAS SOCIAIS - SOCIAL MEDIA MINING}

O conceito de mineração de conteúdos em mídias sociais ou social media mining (SMM) é, em sua essência, o de um processo de mineração web (web mining) e envolve o desenvolvimento de ferramentas e aplicação de técnicas para coletar, monitorar, analisar, resumir e visualizar conteúdos de mídias sociais (Zeng, Chen, Lusch \& Li, 2010; Sakaki, Okazaki \& Matsuo, 2010; Zafarani, Abbasi \& Liu, 2014).

Crooks, Croitoru, Stefanidis e Radzikowski (2013) estruturam a SMM em três etapas gerais, a saber: i) extração de dados dos provedores e servidores de mídias sociais através das interfaces de programação de aplicativos (API); ii) análise, integração e armazenamento de dados; e iii) análise dos dados para extrair informações de interesse.

A aplicação do SMM oferece oportunidades para descobrir e identificar padrões, características, informações e tópicos relevantes; originar perspectivas interessantes para a compreensão do comportamento humano; realizar análises qualitativas e quantitativas e até mesmo prever eventos futuros a partir de conteúdos não estruturados. Para tanto requer acompanhamento e refinamento contínuo de procedimentos e informações, visando contornar às principais características desse tipo de dados: grandes, barulhentos e dinâmicos (large, noisy, and dynamic) (Zeng, Li \& Duan, 2012). 
Crooks, Croitoru, Stefanidis e Radzikowski (2013) ressaltam que existem diversas ferramentas e sites que executam parte destes processos de monitoramento em mídias sociais, mas que a grande maioria são limitados em relação ao tratamento de grandes conjuntos de dados. Com esse diagnóstico, é exigido o desenvolvimento de sistemas personalizados para executar as etapas de descoberta de conhecimento a partir de conteúdos de mídias sociais.

Laine e Fruhwirth (2010) acrescentam que essas ferramentas de monitoramento de mídias sociais são serviços de software oferecidos através da Internet para filtrar e analisar o conteúdo textual produzido por e na mídia social. Elas recuperam o conteúdo com base em palavras-chave definidas pelo usuário e incorporam funcionalidades como: análise de volume, fonte, autor, palavra-chave, região, sentimento e oferecem opções para análises, gerar relatórios, gráficos, entre outros.

Sendo assim, a tarefa de encontrar informações relevantes na Internet é muito difícil e muitas vezes se torna uma experiência frustrante devido à heterogeneidade e à falta de estrutura de dados. Portanto, a descoberta automatizada de informação em conhecimento apresenta problemas de pesquisa desafiadores.

\section{METODOLOGIA}

Na presente pesquisa foi utilizada uma abordagem qualitativa de caráter exploratório e descritivo. O processo de mineração de conteúdos em mídias sociais para auxiliar na gestão de destinos turísticos foi elaborado com base nas metodologias propostas por Neves e Marchiori (2014), Hea, Zha e Li (2013), Kalampokis, Tambouris e Tarabanis (2013) e Abrahams et al. (2013). Para complementar e embasar o processo proposto, os modelos de Knowledge Discovery in Databases (KDD) de Fayyad, Piatetsky-Shapiro e Smyth (1996), Han, Pei \& Kamber (2011) e Chapman et al. (2000) também foram explorados. 
As diversas abordagens quanto a estrutura de SMM, bem como dos modelos de KDD, foram extraídos, combinados e resultaram em uma nova metodologia voltada à gestão de destinos turísticos, composta por sete fases. As fases e etapas foram sintetizadas e apresentadas em um diagrama, conforme descrito na Figura 1.

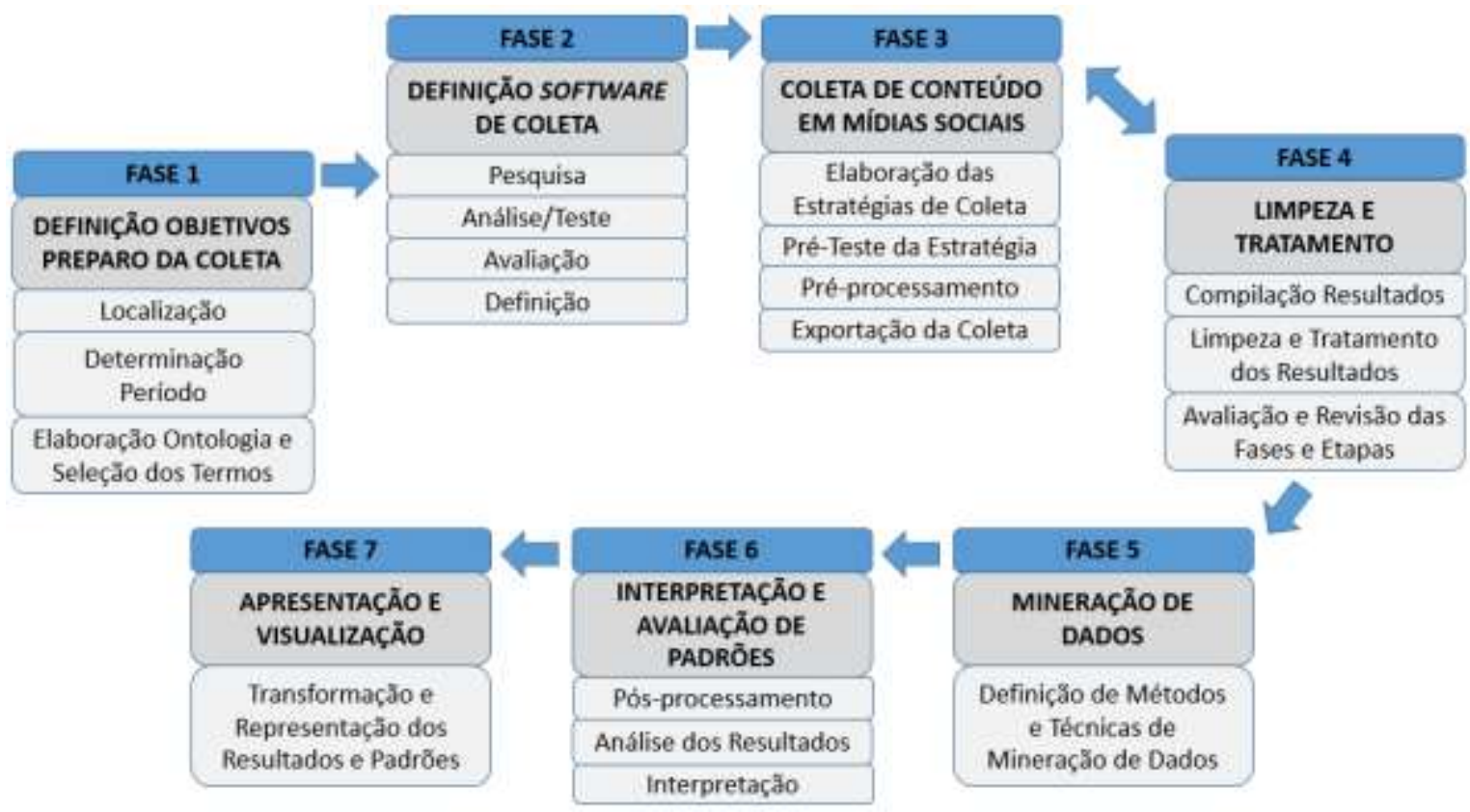

Figura 1. Processo de mineração de conteúdos em mídias sociais para auxiliar na gestão de destinos turísticos

Fonte: Elaborado pelos autores (2016)

Na fase inicial são definidos os objetivos, o problema e os limites do monitoramento. Para alcançar o conteúdo referente à esses atrativos foi elaborada uma ontologia de domínio, onde cada atrativo estava associado à um conjunto de termos que poderiam levar até ele. Ex. O museu Oscar Niemeyer também é conhecido como "Museu do Olho" ou pela sigla "Mon"; os três termos foram buscados nas mídias sociais, além de suas variantes em inglês e português, para juntos compor uma unidade de sentido na pesquisa chamada Atrativo Museu Oscar Niemeyer.

O processo foi aplicado e verificado a partir da mineração de conteúdos publicados pelos usuários sobre os atrativos turísticos do destino Curitiba (PR), na mídia social Twitter, nos seguintes intervalos relativos ao evento Copa do 
Mundo FIFA 2014: Pré-Sorteio (16 de setembro de 2013 até 25 de novembro de 2013.), Sorteio (26 de novembro de 2013 até 31 de janeiro de 2014), Pré-Copa A $(01$ de fevereiro de 2014 até 31 de março de 2014), Pré-Copa B (01 de abril até 10 de junho de 2014), Copa (11 de junho de 2014 até 15 de julho de 2014), Pós-Copa (16 de julho de 2014 até 31 de agosto de 2014).

Quanto à seleção dos atrativos turísticos, foi necessário definir um critério de corte devido a quantidade de atrativos turísticos na cidade e, portanto, foi estabelecido o limite de dez atrativos, selecionados com base em sua popularidade no site TripAdvisor. É importante destacar que a popularidade refere-se à quantidade de comentários e não à maior avaliação geral. Sendo assim, foram selecionados: Jardim Botânico; Museu Oscar Niemeyer; Ópera de Arame; Parque Barigui; Estrada da Graciosa; Santa Felicidade; Parque Tanguá; Ilha do Mel; Torre Panorâmica da Oi; Largo da Ordem/Setor Histórico. Esse critério foi adotado após uma análise preliminar de informações disponibilizadas pelas DMOs de Curitiba, que não tinham dados suficientes ou mesmo padronizadas para servir como fonte.

Na definição do software de coleta, entre outras ferramentas, optou-se pelo desenvolvimento próprio de scripts e soluções - conforme indicado no aporte teórico -, para obter maior controle sobre o processo e torna-lo mais eficaz à medida que surgiam os entraves. Somente na fase posterior, a de coleta, que foi utilizada uma empresa (Seekr) exclusivamente para coleta dos dados nas mídias sociais. Toda análise e estruturação foi realizada pelos autores. Na fase de limpeza e tratamento foram extraídas diversas amostras e verificadas inconsistências, principalmente associadas a termos homônimos. Para solucionar esses casos, novas regras foram incluídas nos scripts de processamento. Dentre os conteúdos coletados, analisou-se uma amostra de 942 publicações de usuários sobre os atrativos turísticos de Curitiba.

Durante a fase de mineração, os dados coletados foram categorizados, tendo como base a mesma ontologia de domínio, ainda com constante necessidade de verificação, por amostras, da consistência dos dados. Na análise dos resultados foram realizadas contagens e os dados foram 
sumarizados de acordo com o objetivo do estudo, gerando alguns gráficos que permitem construir hipóteses sobre o cenário de atrativos do destino. Na última fase, foram realizados alguns experimentos para representar os resultados com diagramas não convencionais, como é o caso de mapas heurísticos.

\section{ANÁLISE E DISCUSSÃO DE RESULTADOS}

Os atrativos turísticos de Curitiba presentes na ontologia foram investigados para medir sua popularidade nos períodos supracitados e de interesse da pesquisa. A média de ocorrências por dia dos dez principais atrativos do destino Curitiba são elencados na Figura 2.

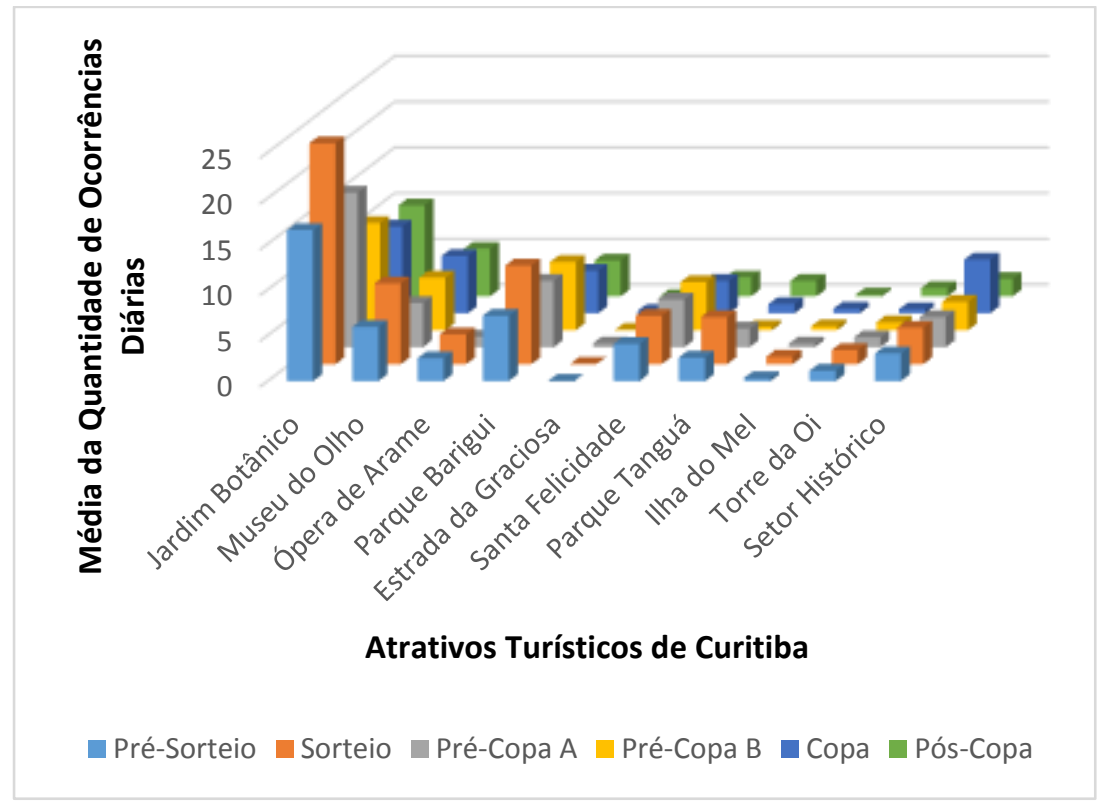

Figura 2. Quantidade média de ocorrências diárias dos atrativos turísticos de Curitiba Fonte: Elaborado pelos autores (2016)

Através da análise do quadro, identifica-se que o Jardim Botânico foi o atrativo turístico mais mencionado nas publicações coletadas, seguido do Parque Barigui, Museu Oscar Niemeyer, Bairro de Santa Felicidade e Largo da Ordem (Setor Histórico de Curitiba). Este é um importante indicador sobre os principais e mais populares atrativos turísticos da cidade de Curitiba. 
Cabe ressaltar que a maior quantidade de ocorrências nas publicações monitoradas ocorreu durante o período Sorteio e Pré-Copa A. Isso pode ter sido motivado pela divulgação da localidade dos jogos da Copa do Mundo durante o sorteio, período em que a mídia e os meios de comunicação global passam a publicar e divulgar matérias sobre as cidades-sede com pautas sobre atrações turísticas, entre outros.

Além disso, a quantidade de ocorrências nos períodos mencionados pode ter sido influenciada pelo fato de corresponderem ao verão, férias escolares e a alta temporada do Turismo no Brasil (26 de novembro de 2013 a 31 de março de 2014). Com isso, mais pessoas e turistas podem ter visitado os atrativos turísticos de Curitiba e compartilhado suas experiências de viagem nas mídias sociais.

Nota-se também que a incidência foi ligeiramente menor nos períodos Copa e Pós-Copa $(11$ de junho até 31 de agosto de 2014) e pode ter sido influenciado pelo foco e atenção voltada aos jogos da Copa do Mundo, evento que não obrigatoriamente atrai a atenção de todos turistas, haja vista que a realização do evento acarretou alta nos preços dos produtos e serviços turísticos como transporte, hospedagem, alimentação, entre outros.

Através da análise de conteúdo das publicações de atrativos em Curitiba, foi possível identificar mensagens relacionadas a eventos sediados na capital paranaense, principalmente no Parque Barigui. A partir desta observação, pode-se afirmar que o parque configura-se como um dos principais locais e espaços para sediar eventos sociais, esportivos, beneficentes, entre outros. Além dele, outros locais de eventos mencionados pelos usuários foram o Jardim Botânico, Museu Oscar Niemeyer e o Bairro de Santa Felicidade, conforme apresentado na Tabela 2.

Tabela 2. Amostra de publicações sobre eventos em Curitiba

\begin{tabular}{|c|l|}
\hline CONTEXTO & \multicolumn{1}{|c|}{ PUBLICAÇÕES } \\
\hline $\begin{array}{c}\text { Parque } \\
\text { Barigui }\end{array}$ & $\begin{array}{l}\text { RT @gleisi: Feira de adoção \"Amigo Bicho\" neste sábado no Parque Barigui, } \\
\text { das 10h às 16h. http://t.co/kftCqbkAjF }\end{array}$ \\
\cline { 2 - 3 } & $\begin{array}{l}\text { RT @cervejacolorado: Alô galera de Curitiba! \\
Neste sábado estaremos no } \\
\text { WikiBier Festival que vai acontecer no Parque Barigui a... http://t... }\end{array}$ \\
\hline
\end{tabular}




\begin{tabular}{|c|c|}
\hline \multirow[t]{3}{*}{ CONTEXTO } & PUBLICAÇÕES \\
\hline & \#BRASILMOTORCYCLESHOW 22,23,24 de Novembro 2013 Parque Barigui Curitiba \\
\hline & $\begin{array}{l}\text { Corrida da Esperança no Parque Barigui - Curitiba, em prol do Criança } \\
\text { Esperança, presença atores da Globo }\end{array}$ \\
\hline \multirow{2}{*}{$\begin{array}{l}\text { Jardim } \\
\text { Botânico }\end{array}$} & $\begin{array}{l}\text { RT @BiebersManiaBR: Atenção Beliebers de Curitiba, semana que vem tem } \\
\text { encontro no Jardim Botânico, não deixem de comparecer!! - https://t.c... }\end{array}$ \\
\hline & $\begin{array}{l}\text { RT @taygalega: Tem alguém de Curitiba aí? Pensei em fazer uma roda de violão } \\
\text { no Jardim Botânico mês que vem quando, aproveitando o rolê. } \\
\text { RT @taygalega: Pra quem tá em Curitiba: chega junto aqui no Museu Oscar } \\
\text { Niemeyer. Vou fazer um som por aqui até umas horas! :D }\end{array}$ \\
\hline \multirow{2}{*}{$\begin{array}{l}\text { Museu } \\
\text { Oscar } \\
\text { Niemeyer }\end{array}$} & $\begin{array}{l}\text { RT @gazetadopovo: Feira gastronômica no MON abre o festival cultural Mia } \\
\text { Cara Curitiba neste sábado. http://t.co/TcW4QL4POW http://t.co/jTx... }\end{array}$ \\
\hline & $\begin{array}{l}\text { RT @taygalega: AMANHÃ (14/12) tem show em CURITIBA-PR! 15hrs, no Museu } \\
\text { Oscar Niemeyer. Me ajudem a espallhar e convidar os amigos. http://t.... }\end{array}$ \\
\hline
\end{tabular}

Fonte: Elaborado pelos autores (2016)

Constatou-se também a popularidade de uma atividade dos usuários nas mídias sociais permitida pelo avanço e desenvolvimento das TICs, tanto do ponto de vista de hardware (dispositivos móveis) quanto de software (aplicativos), denominada "Check-in". Com ela o usuário compartilha os lugares onde está ou esteve como, por exemplo, atrativos turísticos, eventos, bares, restaurantes, hotéis, casas noturnas e, inclusive, pode citar outros usuários que o acompanham. Tal atividade reforça uma tendência em relatar e compartilhar as atividades, hábitos, comportamentos diários e lugares visitados com os demais usuários que o usuário se relaciona nas mídias sociais.

Também foram identificadas publicações de relatos de experiências turísticas positivas e negativas, bem como fotos e vídeos publicados pelos usuários nas mídias sociais, conforme Tabela 3. 
Tabela 3. Relatos de experiências turísticas, fotos e vídeos

\begin{tabular}{|c|c|}
\hline CONTEXTO & PUBLICAÇÔES \\
\hline \multirow{5}{*}{$\begin{array}{c}\text { Experiências } \\
\text { Turísticas } \\
\text { Positivas }\end{array}$} & Curitiba Paraná , Parque Barigui ,lindo lindo lindoo!!!!! http://t.co/BxDfaRsksU \\
\hline & $\begin{array}{l}\text { Hoje faz uma semana que viajei pra curitiba... foi muito bom lá, na ilha do mel } \\
\text { também }\end{array}$ \\
\hline & $\begin{array}{l}\text { RT @rebeccavenn: Great day on Ilha do Mel!! @lonelyplanet \#brazil \#curitiba } \\
\text { http://t.co/PNPOLCOyPR }\end{array}$ \\
\hline & $\begin{array}{l}\text { Viagem para o Sul (Paraná) foi inesquecível. Lindas paisagens em Curitiba e } \\
\text { llha do Mel (= }\end{array}$ \\
\hline & $\begin{array}{l}\text { RT @Chpaiva: Baladinha, feirinha, túnel do rock, ilha do mel, praças, Morretes. } \\
\text { Passeios diversos... Frio e calor; foi massa estar em Curitiba }\end{array}$ \\
\hline \multirow{2}{*}{$\begin{array}{c}\text { Experiências } \\
\text { Turísticas } \\
\text { Negativas }\end{array}$} & $\begin{array}{l}\text { A Estrada da Graciosa que liga Curitiba ao litoral é muito antiga e é lindíssima. } \\
\text { Não recuperá-la e nem cuidar dela como se deve é um crime. }\end{array}$ \\
\hline & em passar \\
\hline \multirow[t]{3}{*}{ Fotos } & $\begin{array}{l}\text { Visão panorâmica \&lt;3 linda \#trip \#love \#city \#brazil \#cool @ Torre } \\
\text { Panoramica De Curitiba! http://t.co/5EEj9dHdtN }\end{array}$ \\
\hline & Turistando \#cwb @ Opera De Arame Curitiba http://t.co/KD5Jvld6Le \\
\hline & $\begin{array}{l}\text { RT @cassi_jones: panorâmica ontem à noite no Parque } \\
\text { Bariguihttp://t.co/TXOHfOC7GB \#photo \#flickr \#curitiba (c/c @Curitiba_PMC } \\
\text { @curitibanic... }\end{array}$ \\
\hline
\end{tabular}

Fonte: Elaborado pelos autores (2016)

Os exemplos apresentados no quadro anterior corroboram 0 entendimento que os usuários compartilham suas experiências turísticas, opiniões, críticas, recomendações, fotos e vídeos nas mídias sociais. Outra característica presente nas mensagens foi a utilização de hashtags (\#), uma prática de categorização do conteúdo com linguagem natural.

Em relação às publicações de promoção turística, recomendações, novidades, dicas de viagem e atividades no destino, além de conversas entre usuários, outros atores locais envolvidos no desenvolvimento da atividade turística também foram identificados nas mídias sociais, publicando sugestões e dicas aos usuários e visitantes da cidade. Na Tabela 4 são apresentados exemplos. 
Tabela 4: Recomendações, novidades, dicas de viagem e atividades sugeridas em Curitiba

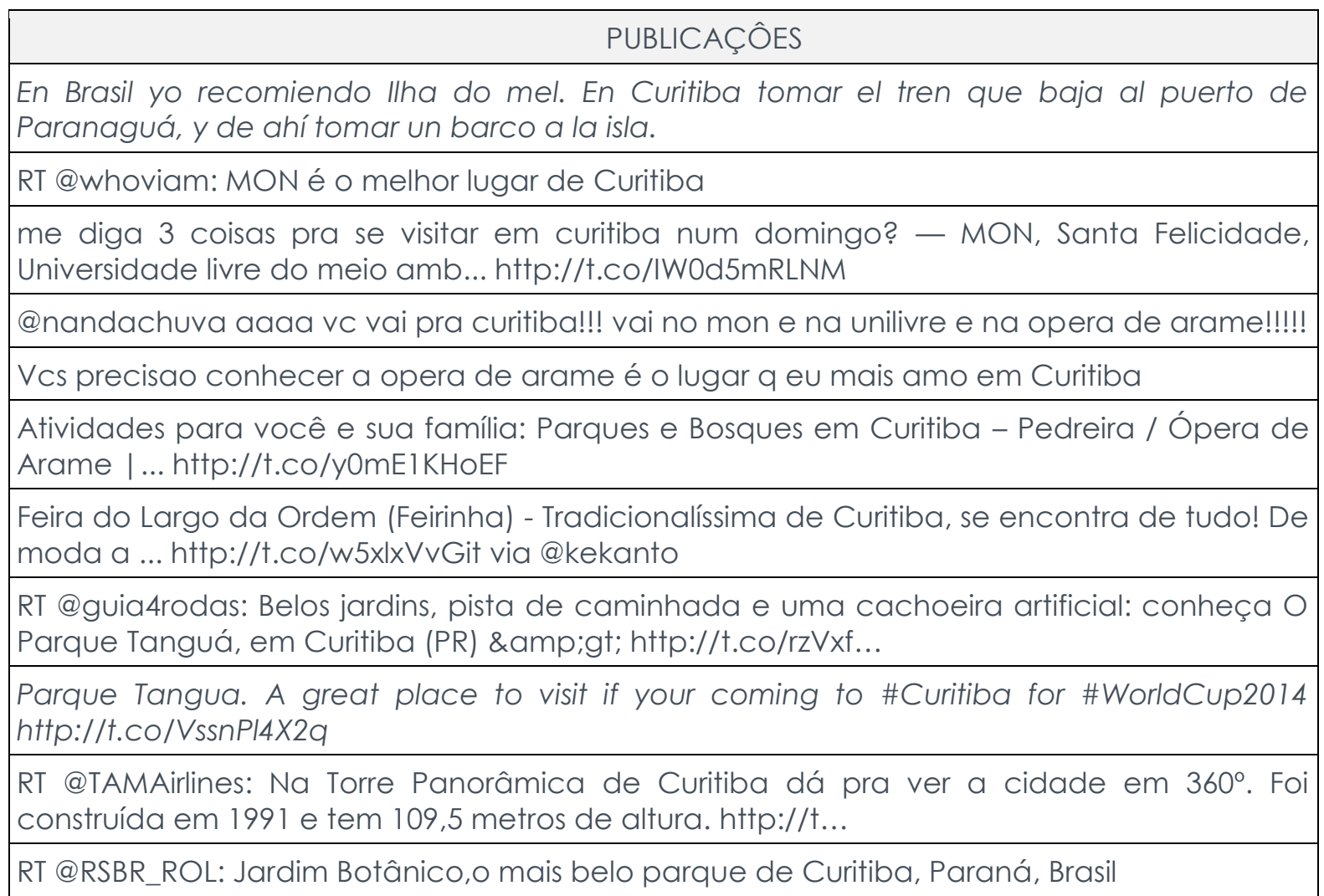
Fonte: Elaborado pelos autores (2016)

A intenção direta ou indireta dos usuários em visitar determinado destino turístico no futuro por meio do compartilhamento da viagem marcada, bem como os destinos que serão visitados, também esteve presente, conforme apresentado na Tabela 5.

Tabela 5. Recomendações, novidades, dicas de viagem e atividades sugeridas em Curitiba

\begin{tabular}{|c|c|}
\hline CONTEXTO & PUBLICAÇÕES \\
\hline \multirow{2}{*}{$\begin{array}{c}\text { Intenção } \\
\text { de } \\
\text { Visita }\end{array}$} & $\begin{array}{l}\text { em maio vo fazer uma viagem com a galera do trampo la pra ilha do mel em } \\
\text { curitiba vai ser muito massa haushauhsaushaushashua }\end{array}$ \\
\hline & Vou programar minha próxima viagem pra Curitiba / Ilha do Mel / Morretes \\
\hline \multirow{6}{*}{$\begin{array}{l}\text { Outros } \\
\text { Destinos }\end{array}$} & $\begin{array}{l}\text { Bye bye Curitiba.... Next stop Ilha do Mel :) (@ Rodoferroviária de Curitiba - } \\
\text { @curitiba_pmc w/ } 17 \text { others) [pic]: }\end{array}$ \\
\hline & $\begin{array}{l}\text { RT @marcel_so: indo pra curitiba visitar o jardim botanico a opera de arame e o } \\
\text { adriano }\end{array}$ \\
\hline & Vamos direto pra llha do Mel, e na volta vamos passar em Balneário e Curitiba... \\
\hline & Curitiba - guaratuba - ilha do mel - itapoá \\
\hline & Saindo de Curitiba em direção a ILHA DO MEL \#feriadão \\
\hline & $\begin{array}{l}\text { E começa a viagem de fds... Rumo Curitiba e Ilha do Mel. (@ Itapevi) } \\
\text { http://t.co/LT8DMg9abq }\end{array}$ \\
\hline
\end{tabular}




\begin{tabular}{|l|l|}
\hline CONTEXTO & \multicolumn{1}{|c|}{ PUBLICAÇÕES } \\
\hline \multirow{2}{*}{$\begin{array}{l}\text { En mi paso fugaz por Brasil fui a: Foz de Iguazu, Curitiba, Morretes, Ilha do Mel y } \\
\text { Floriaponopolis...creo q me faltan Iugares, no recuerdo }\end{array}$} \\
\cline { 2 - 2 } & $\begin{array}{l}\text { Rio, Porto Alegre + Curitiba flights + accommodation booked for @FifaWorldCup } \\
\text { 2014. \#RoadToBrazil I'm ready @Socceroos }\end{array}$ \\
\hline
\end{tabular}

Fonte: Elaborado pelos autores (2016)

De forma geral, o conteúdo das mensagens oferece oportunidades às DMOs para interagirem com os usuários e proporcionarem uma experiência prévia ou, até mesmo, surpreendê-los com conteúdo, produtos, serviços turísticos exclusivos e de acordo com o perfil do mesmo. As DMOs também podem mapear a experiência do usuário e os destinos que serão visitados, reunindo informações estratégicas para propor iniciativas, traçar diretrizes e realizar parcerias entre destinos turísticos, com o objetivo de fortalecer o crescimento e desenvolvimento da atividade turística na região.

\section{CONSIDERAÇÕES FINAIS}

Através do presente estudo foi possível constatar a importância, os benefícios e oportunidades que as mídias sociais podem oferecer à atividade turística, que vão além da comunicação, marketing, promoção e comercialização de produtos, serviços e destinos turísticos. Portanto, pode-se afirmar que as mídias sociais podem ser eficazes e assumir um importante papel na gestão, planejamento, desenvolvimento e fomento da atividade turística.

Buscando explorar como os conteúdos relacionados a turismo publicados pelos usuários nas mídias sociais poderiam ser utilizados estrategicamente pelas DMO, o presente estudo contribui na discussão e crescimento da temática de mineração de conteúdos em mídias sociais na literatura do turismo, partindo de trabalhos anteriores na área de SMM e KDD e realizando um teste empírico.

O processo proposto foi verificado a partir da mineração de conteúdos no Twitter associados aos atrativos turísticos do destino Curitiba, e mostrou-se 
eficaz para coleta, tratamento e análise de atrativos turísticos mais populares. Especificamente para a cidade de Curitiba, a contribuição prática do presente estudo está associada a identificação dos atrativos turísticos mais comentados, bem como das críticas e problemas relatados pelos usuários e visitantes. Além disso, apesar do presente processo não empregar análise de sentimentos, as DMO podem avançar no emprego de técnicas mais robustas, ou mesmo, realizar estudos dirigidos, com enfoque em uma determinada temática ou atrativo.

Outra contribuição prática alcançada no presente estudo foi a identificação de tendências, confirmando algumas características do comportamento do consumidor em turismo nas mídias sociais como: a utilização de hashtags (\#), realização de "check-ins" em atrativos turísticos, busca e compartilhamento de dicas, informações, sugestões, relatos e experiências positivas e negativas.

Como fatores limitantes para o desenvolvimento da pesquisa destacamse dois. O primeiro é o conjunto de limitações de privacidade em relação às mensagens, pelo qual os provedores (neste caso, o Twitter) só disponibilizam o conteúdo que é totalmente público, algo que pode distorcer a composição dos resultados. O segundo refere-se a extensão dos dados coletados, o que impossibilitou a realização da análise de conteúdo para todas as mensagens.

\section{REFERÊNCIAS}

Abrahams, A. S., Jiao, J., Fan, W., Wang, G. A., \& Zhang, Z. (2013). What's buzzing in the blizzard of buzz? Automotive component isolation in social media postings. Decision Support Systems, 55(4), 871-882.

Carson, D. (2008). The 'blogosphere' as a market research tool for tourism destinations: A case study of Australia's Northern Territory. Journal of Vacation Marketing, 14(2), 111-119.

Chapman, P., Clinton, J., Kerber, R., Khabaza, T., Reinartz, T., Shearer, C., \& Wirth, R. (2000). CRISP-DM 1.0 Step-by-step data mining guide.

Chua, A. Y. (2011). How Web 2.0 supports customer relationship management in Amazon. International Journal of Electronic Customer Relationship Management, 5(3/4), 288. 
Chua, A. Y., \& Banerjee, S. (2013). Customer knowledge management via social media: The case of Starbucks. Journal of Knowledge Management, 17(2), 237-249.

Coutinho, F. C; Lang, A. \& Mitschang, B.. Making Social Media Analysis more efficient through Taxonomy Supported Concept Suggestion. In: 15th GI-Symposium Database Systems for Business, Technology and Web, 11 th March - 15th March, 2013. p.457-476.

Crooks, A., Croitoru, A., Stefanidis, A., \& Radzikowski, J. (2012). \#Earthquake: Twitter as a Distributed Sensor System. Transactions in GIS, 17(1), 124-147.

Dwyer, L., Edwards, D., Mistilis, N., Roman, C., \& Scott, N. (2009). Destination and enterprise management for a tourism future. Tourism Management, 30(1), 63-74.

Dey, L., Haque, S. M., Khurdiya, A., \& Shroff, G. (2011, September). Acquiring competitive intelligence from social media. In: Proceedings of the 2011 joint workshop on multilingual OCR and analytics for noisy unstructured text data (p. 3). ACM.

Fayyad, U., Piatetsky-Shapiro, G., \& Smyth, P. (1996). From data mining to knowledge discovery in databases. Al magazine, 17(3), 37.

Gretzel, U., \& Yoo, K. H. (2008). Use and impact of online travel reviews. Information and communication technologies in tourism 2008, 35-46.

Governatori, G., \& lannella, R. (2011). A modelling and reasoning framework for social networks policies. Enterprise Information Systems, 5(1),

Han, J., Pei, J., \& Kamber, M. (2011). Data mining: concepts and techniques. Elsevier.

He, W., Zha, S., \& Li, L. (2013). Social media competitive analysis and text mining: A case study in the pizza industry. International Journal of Information Management, 33(3), 464-472.

Hu, M., \& Liu, B. (2004). Mining and summarizing customer reviews. Proceedings of the 2004 ACM SIGKDD International Conference on Knowledge Discovery and Data Mining - KDD '04.

Kalampokis, E., Tambouris, E., \& Tarabanis, K. (2013). Understanding the predictive power of social media. Internet Research, 23(5), 544-559.

Kaplan, A. M., \& Haenlein, M. (2010). Users of the world, unite! The challenges and opportunities of Social Media. Business horizons, 53(1), 59-68.

Ku, L., \& Chen, H. (2007). Mining opinions from the Web: Beyond relevance retrieval. Journal of the American Society for Information Science and Technology, 58(12), 1838-1850.

Laine, Mikko OJ; Frühwirth, Christian. (2010). Monitoring social media: tools, characteristics and implications. In: Software Business. Springer Berlin Heidelberg.193-198.

Lau, K. (2005). Text Mining for the Hotel Industry. Cornell Hotel and Restaurant Administration Quarterly, 46(3), 344-362.

Magnier-Watanabe, R., Yoshida, M., \& Watanabe, T. (2010). Social network productivity in the use of SNS. Journal of Knowledge Management, 14(6), 910-927.

Munar, A. M. (2012). Social Media Strategies and Destination Management. Scandinavian Journal of Hospitality and Tourism, 12(2), 101-120. 
Neves, A. W., \& Marchiori, P. Z. (2014). Qualidade percebida de produtos e serviços turísticos em eventos técnicas e ferramentas para análise de conteúdo do Twitter. Revista Turismo e Desenvolvimento, 2(21-22), 173-182.

Paine, K. D. (2011). Measure what matters: Online tools for understanding customers, social media, engagement, and key relationships. Hoboken, NJ: Wiley.

Pulvirenti, M., \& Jung, T. (201 1). Impact of Perceived Benefits of Social Media Networks on Web Quality and E-satisfaction. Information and Communication Technologies in Tourism 201 1, 513524.

Roque, V.; Fernandes, G. \& Raposo, R. (2012). Identificação dos Media Sociais utilizados pelas organizações de gestão de destinos: o caso de estudo do destino turístico Serra da Estrela. Revista Turismo \& Desenvolvimento, (17-18), 226-234.

Sakaki, T., Okazaki, M., \& Matsuo, Y. (2010, April). Earthquake shakes Twitter users: real-time event detection by social sensors. In Proceedings of the 19th international conference on World wide web (pp. 851-860). ACM.

Santos, R. (2009). Conceitos de Mineração de Dados na Web. XV Simpósio Brasileiro de Sistemas Multimídia e Web (81-124).

So, K. K., King, C., Sparks, B. A., \& Wang, Y. (2014). The Role of Customer Engagement in Building Consumer Loyalty to Tourism Brands. Journal of Travel Research, 55(1), 64-78.

Torres, C. (2009). A Bíblia do Marketing Digital. São Paulo: Novatec.

Uden, L., Wang, L.S.L., Rodriguez, J.M.C., Yang, H.C. \& Ting, I.H. (2013). The 8th International Conference on Knowledge Management in Organizations: Social and Big Data Computing for Knowledge Management. Springer Netherlands.

Xiang, Z., \& Gretzel, U. (2010). Role of social media in online travel information search. Tourism management, 31 (2), 179-188.

Zafarani, R., Abbasi, M. A., \& Liu, H. (2014). Social media mining: an introduction. Cambridge University Press.

Zeng, B., \& Gerritsen, R. (2014). What do we know about social media in tourism? A review. Tourism Management Perspectives, 10, 27-36.

Zeng, D., Chen, H., Lusch, R., \& Li, S. H. (2010). Social media analytics and intelligence. IEEE Intelligent Systems, 25(6), 13-16.

Zeng, L., Li, L., \& Duan, L. (2012). Business intelligence in enterprise computing environment. Information Technology and Management, 13(4), 297-310.

Yu, S. \& Kak, S. (2012). A survey of prediction using social media. Disponível em: http://arxiv.org/abs/1203.1647. 